\title{
A CASE OF CYSTICERCOSIS, TEMPORAL LOBE EPILEPSY, AND TRANSVESTISM
}

\author{
BY \\ BRIAN M. DAVIES and F. S. MORGENSTERN \\ From the Bethlem Royal Hospital and Maudsley Hospital, London
}

The purpose of this paper is to present, in some detail, the case history of a patient who developed transvestism in association with cerebral cysticercosis. This association does not appear to have been reported previously and, as this man's sexual development was normal until the onset of the transvestism, we believe that this case history presents many unique features. The presence of a number of different temporal lobe aurae and the association of these with a desire to transvest suggests that, while widespread cerebral lesions are presumably present, the temporal lobe foci are particularly concerned in producing the transvestism. In addition, brief case histories of four other patients in whom the association of temporal lobe lesions and abnormalities of sexual behaviour have occurred are presented.

\section{Case Report}

A 36-year-old professional man was referred for psychiatric treatment because of transvestism of some three years' standing. Cysticercosis was diagnosed in 1952, though its manifestations had been present since 1947.

The paternal family history is that of an enterprising, well-adapted family. The patient's father was 63 when he died of chronic bronchitis in 1957. He had taught his son skill in games and the patient looked to him as an example when growing up. His maternal grandmother died in a mental hospital and the diagnosis is said to have been "senile psychosis". His mother died of "presenile dementia" at the same hospital in 1959, while the patient was under observation. She was 64 and had been in hospital since 1954 . The symptoms of her dementing illness began in 1946, before which she had been a reserved but charming and intelligent woman, whom the patient had admired and loved. He had only one sibling, a boy two years his senior, who died at the age of 4 when both he and the patient had pneumonia.

The patient was born at home after a normal delivery. Development was normal and he had shown no neurotic traits during childhood. He did well at a village school and later, at a grammar school, where he stayed until the age of 17. During these years he became very interested in cricket, and this has remained his hobby up to the onset of the present illness.
He had masturbated in adolescence, but without severe guilt feelings. His sexual interests were heterosexual and no evidence of homosexual, fetichistic, or transvestist ideas can be obtained. At the age of 12 he had had to take the part of a king in a nativity play, which involved wearing long, flowing robes. This is the only incident of anything approaching altered clothing that could be obtained. He says, in retrospect, that he felt "terribly silly" on the stage.

At the age of 17 he became a bank clerk and remained at the bank until he joined the Army in 1942 at the age of 19. In January, 1943, he was sent to India and soon after his arrival there developed a chronic mild diarrhoea, which persisted until his return to Europe at the end of the war. In June, 1943, he had an attack of infective hepatitis associated with a single major convulsion at the height of the fever. He then served in Burma, where he saw front-line service until his demobilization in 1946.

On his return to the bank in 1946, he met his future wife and they were engaged for three years before they were married.

In June, 1947, he had a nocturnal grand-mal seizure and a further one while out walking the next day. Of the latter, his memory is quite clear. He knew that something was about to happen and tried to tell his wife. She recollects that his mouth was working as though he wanted to speak and that then he fell down in a generalized convulsion. After the fit he was weak for some hours. A month later he had five or six major seizures within 48 hours. Before the first, he was sitting down to tea, felt the epileptic premonition, and moved to an armchair. He then saw the vision of a polar bear pass slowly from right to left about three yards ahead of him. It was not coloured and there were no emotional accompaniments. The remaining fits of this series were separated by long and deep sleep, and finally he was sent as an emergency admission to the local hospital. Full investigations, including lumbar puncture and a skull radiograph, showed no abnormality and a diagnosis of idiopathic epilepsy was made and anticonvulsant drugs prescribed.

Two other epileptic manifestations date from this period. First, episodes of paraesthesiae localized to the territory of the left maxillary nerve, and lasting five to 15 minutes; this always led him to expect an attack which was not always forthcoming. Secondly, a form 
of dyspraxia, in which the action he happened to be performing was interrupted at a certain point, and however much he attempted to overcome this, he would be unable to proceed beyond the "fixed point". Thus, on the first occasion he was counting out series of 20 , but could not continue after 17. There was a gap in the series of numbers. In a different form this was repeated at meals; lifting his fork to his mouth, it would not go as far as his lips; or on another occasion, he could not write the last sentence of a letter, yet was able to dictate it to his wife.

In 1952, a diagnosis of cysticercosis was made, calcified cysts being shown on radiography of the thighs. As a result he was awarded a $30 \%$ disability pension from the Army.

A whole series of epileptic manifestations occurred between 1953 and 1956 . These included attacks of an altered state of feeling with a totally uncharacteristic longing to go to Burma; this was associated with the olfactory hallucination of a specific Indian bazaar, and some hours later, an epileptic convulsion. Another aura which did not lead to full jactitations but only to altered consciousness and some muscle jerking, of which he remained aware, was a change in his body image, in which he seemed to grow unusually tall. On two occasions, his wife reports brief, violent rages of which he has only the dimmest memory and for which there was no external precipitant.

In 1949 he married and sexual relations were, from the first, normal in all respects. A child was born in 1951.

In 1955 he became attracted to one of the clerks, mainly, he said, because she wore attractive clothing, and at this time he specifically asked his wife to wear frilly, attractively-coloured underwear.

In 1955 he had one grand mal seizure but has had none since.

One afternoon in February, 1956, he suddenly experienced a sensation as if he had received a blow in the stomach, and soon afterwards there was a pulling sensation in the jaws, followed by an impulse to dress in female clothes. On the way home from work, he bought some female underwear and secretly put it on when he reached home. He then felt " completely calm" for a few minutes, then he experienced a feeling of revulsion and later that night burnt the clothes. There was no major seizure and this was the first occasion that an epigastric aura had occurred.

Throughout 1956 and 1957, he had episodic desires to transvest, at first every few months, later nearly every day. On all occasions this desire was ushered in by epigastric and jaw sensations. He became increasingly irritable and normal sexual activity slowly diminished over these years. The feeling of calmness when transvested was uniformly profound and had a compelling quality about it.

In 1958, the desire to transvest became more persistent and started to occur without the epigastric sensations. It was now impossible for him to hide the transvestist activity from his wife, and though he worked efficiently at the bank all day, he would spend the evening at home completely dressed in female clothes, using cosmetics and adopting female mannerisms. He became more depressed and related his illness to the psychotic illnesses of his mother and grandmother. He began to contem- $z$ plate suicide and psychiatric advice was finally sought.

On examination, there was no physical abnormality except for a subcutaneous nodule behind the left ear. \& He was mildly depressed but he was fully alert and $\hat{0}$ obviously of good intelligence (I.Q. 127-Wechsler). 0 He was of athletic physique and, while in hospital, he joined in all sporting activities. He dressed normally $\stackrel{\overbrace{}}{工}$ and no female mannerisms were observed. The desire to transvest was occasionally very strong, but to people unacquainted with his history, he appeared in every way $\Rightarrow$ normal.

Investigations showed that there were numerous 0 calcified cysts in the thighs and pelvis, though none could $\overline{0}$ be positively identified on the skull radiographs. Electro- $\frac{\omega}{\sigma}$ encephalography (with bilateral temporal sphenoidal $\overparen{\mathbb{D}}$ recordings) showed no abnormality other than one $\triangle$ isolated spike in the record obtained from the right $\%$ temporal region. Investigatory psychoanalytically $\vec{O}$ orientated interviews could reveal no definite evidence of abnormalities in sexual development. In all respects, $\overrightarrow{\vec{\omega}}$ before the onset of transvestism, his sexual life was well $\stackrel{\omega}{\circ}$ within normal limits.

The patient has now been under observation for a year, and the desire to transvest is now slightly more if persistent than it was. In hospital this desire could be $\omega$ curbed, but at home, it cannot. Treatment had included is psychotherapy and an attempt to produce an unpleasa ${ }^{t} \pm$ emotion when he transvests by methods of conditionine $\mathrm{O}$ To date these attempts have been unsuccessful. The will be reported in detail elsewhere.

\section{Discussion}

There can be no doubt that this man has calcifie $\overrightarrow{0}$ cysticercus cysts in the thigh muscles and, whife none show on his skull radiograph, the history is such that a diagnosis of cerebral cysticercosis must be made on clinical grounds. The fits, multiple temporal lobe aura, and the transvestism seem to be associated with these lesions. Dixon and $\frac{0}{\varnothing}$ Hargreaves (1944) have followed 284 patients with 0 cysticercosis. Mental abnormalities are mentioned, particularly personality deviations, $5 \%$ of the patients showing evidence of marked mental deterioration (generally secondary to frequent epileptic attacks) sufficient to warrant admission to a mental hospital. Multiple focal phenomena were noted to occuro frequently, as were antisocial acts, but no reference $\frac{0}{7}$ is made to abnormalities in sexual behaviour.

Temporal lobe lesions from other causes have $\delta$ been associated with abnormal sexual behaviour in $₹$ other patients seen at the same hospital and four $\frac{\mathrm{C}}{\mathrm{T}}$ brief case histories describe the relevant features:-

Case 1.-A 13-year-old boy had a left-sided cerebral lesion (with E.E.G. evidence of temporal lobe abnor- $N$ mality), the consequence of a prolonged and difficult delivery. He developed epilepsy at the age of 8 , and at 
the age of 11 began to wear female clothes. In addition, there were behaviour problems at school. He was of low intelligence (I.Q. 86-Wechsler). It is interesting to note that the transvestist activities became prominent as the major seizures were controlled with anticonvulsant drugs.

Case 2. - This patient had a normal childhood and had no major illness until he developed epilepsy at the age of 23, while in the Army. The aurae included sudden confusion, movements of the lips, epigastric sensations, and derealization phenomena. Medication was unsuccessful in controlling the frequency of the fits. Physical examination and radiological studies showed no abnormalities. The E.E.G., however, showed definite right-sided spike discharges. In 1954, at the age of 35, a right temporal lobectomy was performed by $\mathrm{Mr}$. Murray Falconer. A small astrocytoma was found in the right uncal region. This patient's sexual development showed abnormalities in adolescence, when he masturbated while dressed in female underwear. Heterosexual experiences were never successful because of the transvestism, which became more prominent. He had also, some homosexual experiences while he was in the Army. Post-operatively he has recovered completely from the epilepsy. In addition, he has received psychoanalytical treatment for his sexual difficulties with some definite improvement.

Case 3.-An adolescent boy developed slowly in childhood and a diagnosis of spastic quadraplegia was made when he was 2 years old. At the age of 12 he was referred for psychiatric treatment because of aggressive, impulsive behaviour. Transvestism began when he was 13, while under observation. The E.E.G. showed a complex abnormal record that included abnormalities in recordings from both temporal regions.

Case 4.-Temporal lobectomy relieved both the epilepsy and fetichism that were associated in a patient described by Mitchell, Falconer, and Hill (1954).

While the clinical association of transvestism and cerebral pathology is shown by the above case histories, we are not in a position to localize the cerebral disturbances that underlie such abnormalities further than suggesting the importance of mechanisms within the temporal lobes. Such mechanisms have been suggested by experimental work on different species of animals. When bilateral temporal lobe lesions are produced various behavioural changes occur, including changes in sexual behaviour (Klüver and Bucy, 1939; Schreiner and Kling, 1953; Green, Clemente, and De Groot, 1957). The relationship of these associations to the fact that transvestism is probably a widespread phenomenon and the many varied explanations couched in psychological terms that have been offered to explain it (reviewed by Lukianowicz, 1959) remains obscure.

\section{Summary}

A patient is reported with cerebral cysticercosis, in whom the desire to transvest was preceded by temporal lobe aurae. The development of the illness, which has resisted treatment, is described and four other patients are mentioned in whom abnormalities of sexual behaviour were associated with temporal lobe lesions.

We wish to thank Dr. Linford Rees for his advice and for permission to publish this report, the patient being admitted under his care; and to Mr. Murray Falconer and Dr. Pond for permission to mention the other case histories.

\section{REFERENCES}

Dixon, H. B. F., and Hargreaves, W. H. (1944). Quart. J. Med., 37

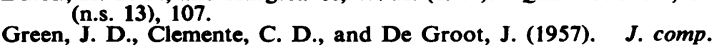
Neurol., 108, 505 .

Klüver, H., and Bucy, P. C. (1939). Arch. Neurol. Psychiat. (Chicago),

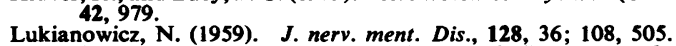

Mitchell, W., Falconer, M. A., and Hill, D. (1954). Lancet, $2,626$. Schreiner, L., and Kling, A. (1953). J. Neurophysiol., 16, 643 . 